\title{
Analysis of the punching behavior of RC flat slabs with horizontal and vertical shear reinforcement
}

\author{
Rasha T. S. Mabrouk ${ }^{1, *}$, and Ali A. Hegab ${ }^{1}$ \\ ${ }^{1}$ Faculty of Engineering, Cairo University, Giza, Egypt
}

\begin{abstract}
Punching failure is one of the major drawbacks of using flat slabs in the design of reinforced concrete structures. Punching shear analysis is very complicated which appears clearly in the large variation of the equations used by the different codes in calculating the punching shear capacity. There are many factors that affect the punching shear capacity of an element. This current research aims to investigate the contribution of two of these factors which are the horizontal flexural reinforcement, and the vertical shear reinforcement in the form of stirrups. Following the experimental program conducted at the reinforced concrete laboratory of the Faculty of Engineering at Cairo University, Egypt and verification using the finite non-linear analysis software (ANSYS 15), good correlation was observed between the analytical models and their corresponding experimental data. This proves that ANSYS 15 allows for studying the punching behavior of the flat slab in more details which could not be monitored in the laboratory. As a result, a detailed parametric study as well as comparison with some design codes was conducted using thirteen full scale flat slab specimens in order to simulate real life problems. The specimens had a loaded span of $2000 \mathrm{~mm}$ and a total thickness of $250 \mathrm{~mm}$. The variables under study were the flexural reinforcement ratio and stirrups spacing and diameter in order to further enhance the understanding of the behavior of flat slabs in punching.
\end{abstract}

\section{Introduction}

Reinforced concrete flat slab is a popular structural system due to its construction advantages. For architectural engineers it has the advantage of freeing them from any constraints in partitioning areas, also, it gives them larger clear floor height. It is preferred by mechanical engineers because it helps them avoid making sleeves in beams to pass mechanical ducts. For site structural engineers, it gives them the benefit of making easier formworks and the ease in placing slab reinforcements. On the other hand, the flat slab has the major drawback of brittle punching shear failure at the slab column connections. The analysis of the flat slab is very complicated due to the large number of variables involved, and the fact that the transfer of loads and stresses from columns to slab goes through

\footnotetext{
* Corresponding author: yrasha@yahoo.com
} 
different elements. Therefore, several researchers have given special attention to the punching behavior of slab column connections.

Analytical, numerical, as well as, extensive experimental studies have been conducted in the past decades to investigate this problem. Moe [1] concluded that the punching shear strength is related to the square root of the concrete compressive strength and then he proposed equations for the calculation of the ultimate nominal punching shear strength. The model presented by Kinnunen and Nylander [2] is one of the first analytical models that depend on the mechanical behavior and properties of slab column connection. This was followed by Kinnunen [3] then Andresson [4] who updated the model to consider the effect of vertical punching reinforcement.

This complexity in design appears clearly in the large variation of the different equations adopted by the design codes in calculating the punching shear capacity. Some design codes take very large factor of safety and other codes neglect some of the elements that can contribute effectively to the punching shear resistance. For example, in the Egyptian Code of practice [5], the effect of the vertical reinforcement and the horizontal reinforcement is not considered in the punching capacity calculation. While, the American code ACI 318R-14 [6] neglects the effect of the horizontal reinforcement. However, the Eurocode [7] considers all of the three parameters.

Hegab and Mabrouk [8] and Hegab [9] studied six half-scale column-slab specimens cast in the concrete laboratory at the Faculty of Engineering, Cairo University. The six specimens had the same concrete dimensions; $1100 \times 1100 \mathrm{~mm}$ slab with thickness $100 \mathrm{~mm}$, and $150 \times 150 \mathrm{~mm}$ column with height $250 \mathrm{~mm}$. The specimens were supported at the four edges and the loaded span was taken as $1000 \mathrm{~mm}$. The specimens were divided into two groups. Group I consisted of three specimens with top and bottom mesh reinforcement with flexural reinforcement ratios of $0.40 \%, 0.55 \%$ and $0.785 \%$. While group II was reinforced with vertical reinforcement in the form of stirrups in addition to the top and bottom mesh used in group I. The details of the specimens are shown in Table 1.

Table 1. Reinforcement details of the six specimens tested [8,9].

\begin{tabular}{|c|c|c|c|c|c|}
\hline Group & Specimen & $\begin{array}{c}\text { Tension } \\
\text { RFT } \\
\end{array}$ & $\begin{array}{c}\text { Compression } \\
\text { RFT } \\
\end{array}$ & Stirrups & Plan \\
\hline \multirow{3}{*}{ I } & S1-1 & $5 \varnothing 10 / \mathrm{m}$ & $5 \varnothing 10 / \mathrm{m}$ & --- & \multirow{3}{*}{ 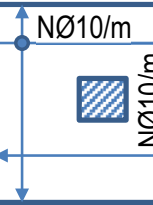 } \\
\hline & S1-2 & $7 \varnothing 10 / \mathrm{m}$ & $7 \varnothing 10 / \mathrm{m}$ & --- & \\
\hline & S1-3 & $10 \varnothing 10 / \mathrm{m}$ & $10 \varnothing 10 / \mathrm{m}$ & --- & \\
\hline \multirow{3}{*}{ II } & S2-1 & $5 \varnothing 10 / \mathrm{m}$ & $5 \varnothing 10 / \mathrm{m}$ & Ø8@100 mm & \multirow{2}{*}{ Ø8@sЕ } \\
\hline & S2-2 & $7 \varnothing 10 / \mathrm{m}$ & $7 \varnothing 10 / \mathrm{m}$ & Ø8@70 mm & \\
\hline & S2-3 & $10 \varnothing 10 / \mathrm{m}$ & $10 \varnothing 10 / \mathrm{m}$ & Ø8@50mm & $E$ \\
\hline
\end{tabular}

They concluded that a significant increase in the punching capacity due to the increase in the flexural reinforcement mesh is observed. The punching ultimate capacity increased by $13.2 \%$ due to the increase in the flexural reinforcement by $40.3 \%$, and it increased by $20 \%$ by doubling the flexural reinforcement ratio. Moreover, there is a noticeable increase in the punching load capacity in group II specimens compared to their corresponding specimens of group I due to the addition of stirrups. This increase is more pronounced in specimen S2-3 (19.5\%) which asserts that the spacing between stirrups is preferred to be limited to a small value $[8,9]$. However, more detailed investigation is needed with more 
variables as well as an in depth study of each of the parameters affecting the punching behavior of flat slabs in order to better understand this kind of behavior.

The main aim of this research is to further study the role of the flexural horizontal reinforcement and the vertical shear reinforcement in the form of stirrups in resisting the punching shear acting on reinforced concrete flat slabs.

\section{Finite element analysis}

The finite element analysis program ANSYS 15 was used in this research. Concrete was modelled using the SOLID65 element which has eight nodes with three degrees of freedom at every node. These are translations in the $\mathrm{x}, \mathrm{y}$, and $\mathrm{z}$ directions. The element is capable of plastic deformation, cracking, and crushing in three orthogonal directions [10]. Figure 1 shows the typical elements used to model both concrete and steel. Concrete material properties are defined in ANSYS as poisons ratio 0.2 and modulus of elasticity 25,200 $\mathrm{MPa}$. The value of the tensile strength is input and an idealized stress strain curve was used to model concrete as shown in Figure 2.

Subsequently, the reinforcement rebar was defined as the discrete element LINK180 which is a three dimensional truss element with two nodes; each node has three degrees of freedom in the form of translation in the three global directions [10] as shown in Figure 1. The material definitions for this steel element are assumed linearly as poisons ratio of 0.3 and modulus of elasticity $200,000 \mathrm{MPa}$. The idealized stress strain curve for steel is shown in Figure 3. While, Figures 4 and 5 show the mesh used for concrete as well as for horizontal steel and vertical stirrups.

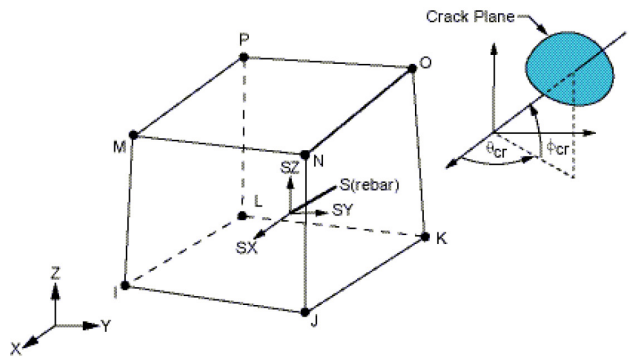

(a) Concrete (element Solid 65)

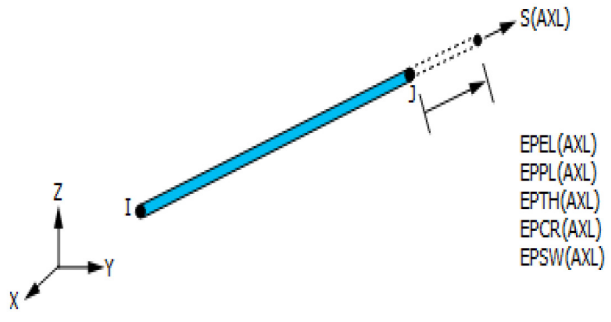

(b) Steel (element Link180)

Fig. 1. Elements used for modelling concrete and steel.

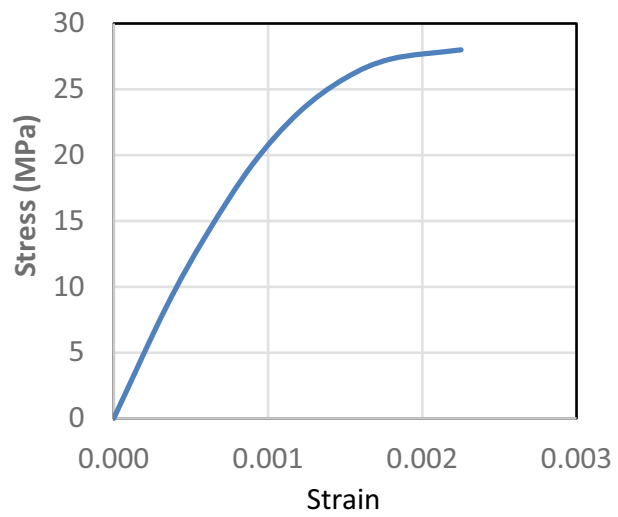

Fig. 2. Idealized compression stress strain curve for concrete.

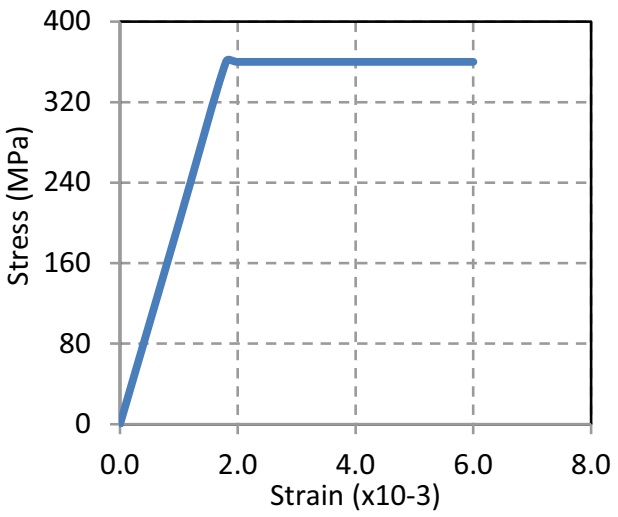

Fig. 3. Idealized stress strain curve for steel. 


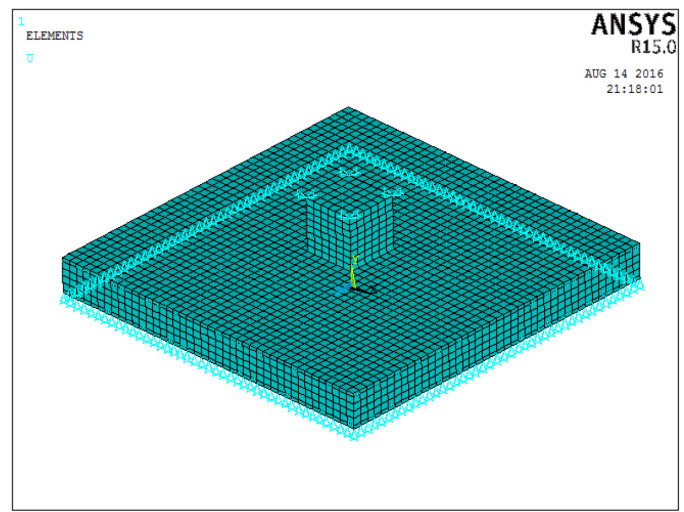

Fig. 4. Mesh used for concrete and boundary conditions.

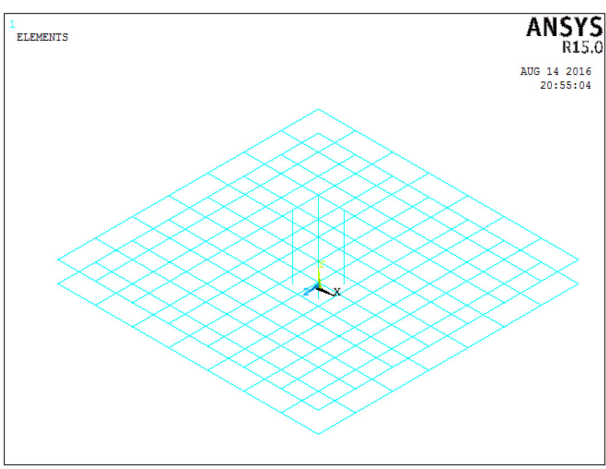

(a) Horizontal reinforcement

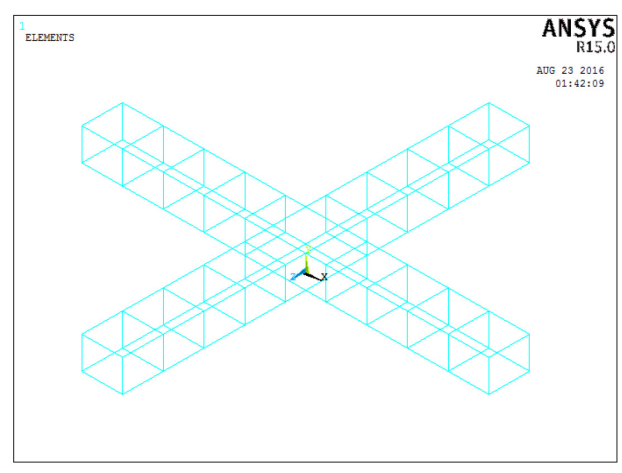

(b) Stirrups

Fig. 5. Mesh used for steel reinforcement.

This study was conducted in two steps. First, the results estimated using the ANSYS program had to be verified against experimental data. Second, a more detailed parametric study was performed to further assess the punching behaviour of the slab-column connections in flat slabs

\subsection{Experimental verification}

As a first step the six slab specimens mentioned in Table 1 were analysed using the nonlinear finite element software (ANSYS 15) [8,9]. Figure 6 and 7 show an example of the load deflection relations for a specimen from Group I and another specimen from Group II, respectively where $S$ refers to the experimental specimens and $M$ refers to the corresponding models using ANSYS 15. Hegab and Mabrouk [8] and Hegab [9] concluded that good correlation can be seen between both the analytical and the experimental data. Comparing the error percentage of the ultimate load and the corresponding deflection between the experimental data and the analytical model, the percentage of error did not exceed $10 \%$ for the ultimate load and $16 \%$ for the deflection which is quite acceptable. 


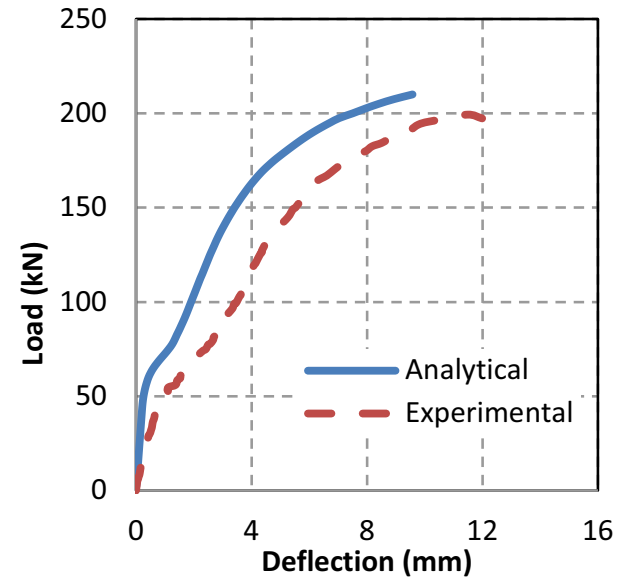

Fig. 6. Load-Deflection curves for S1-3 and M13

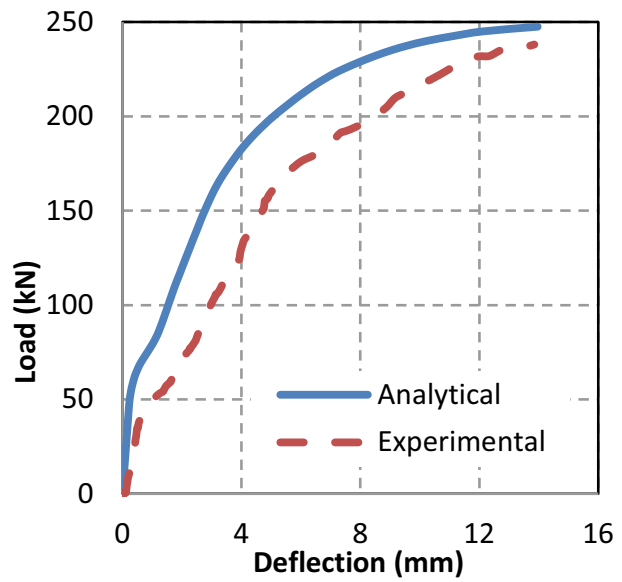

Fig. 7. Load-Deflection curves for S2-3 and M23

\subsection{Parametric study using full scale models}

Based on the results in section 2.1, ANSYS 15 can be utilized to further investigate the effect of the horizontal and vertical reinforcement on the punching behavior of flat slabs. For a better simulation of real life problems, thirteen full scale specimens were studied. All the thirteen specimens were slabs of total dimensions $2100 \times 2100 \mathrm{~mm}$ with a thickness of $250 \mathrm{~mm}$, and $300 \times 300 \mathrm{~mm}$ column with height $250 \mathrm{~mm}$ supported at the four edges as shown in Figure 8. The loaded span was taken as $2000 \mathrm{~mm}$ and the concrete compressive strength as $35 \mathrm{MPa}$. High grade steel $(360 / 520)$ was used. Table 2 and Figure 9 show the details of the thirteen specimens analyzed in this study. The specimens had flexural reinforcement ratios varying from $0.67 \%$ to $2.45 \%$ as well as different arrangements of vertical reinforcement. Specimens S01 to S05 were reinforced with a horizontal mesh with spacing $100 \mathrm{~mm}$. However, the bar diameter was changed from 16 to $25 \mathrm{~mm}$. S06 to S10 had bar spacing of $150 \mathrm{~mm}$ and also varying bar diameters from 16 to $25 \mathrm{~mm}$. All of these ten specimens had no vertical stirrups. In the last three specimens (S11, S12 and S13), stirrups were added. The spacing of the stirrups was changed between S11 and S12 while the diameter of stirrups was taken $12 \mathrm{~mm}$ for S12 and $10 \mathrm{~mm}$ for S13 in order to study the effect of these two parameters on the behavior of the slabs.

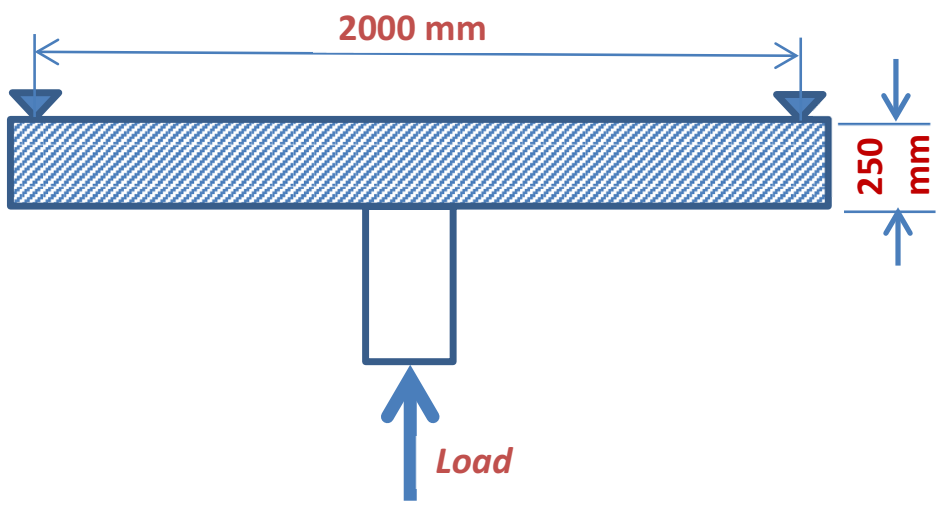

Fig. 8. Schematic representation of the analysed specimens. 
Table 2. Details of all the specimens.

\begin{tabular}{|c|c|c|c|c|}
\hline \multirow{2}{*}{ Specimen } & \multicolumn{3}{|c|}{ Reinforcement } & \multirow{2}{*}{$\begin{array}{c}\text { Horizontal } \\
\text { RFT ratio } \\
\text { (p) } \% \\
\end{array}$} \\
\hline & Top mesh & Bottom mesh & Stirrups & \\
\hline S01 & Ø16@100 mm & Ø16@100 mm & --- & 1.00 \\
\hline S02 & Ø18@100 mm & Ø16@100 mm & --- & 1.27 \\
\hline S03 & Ø20@100 mm & Ø16@100 mm & --- & 1.57 \\
\hline S04 & Ø22@100 mm & Ø16@100 mm & --- & 1.90 \\
\hline S05 & Ø25@100 mm & Ø16@100 mm & --- & 2.45 \\
\hline S06 & Ø16@150 mm & Ø16@150 mm & --- & 0.67 \\
\hline S07 & Ø18@150 mm & Ø16@150 mm & --- & 0.85 \\
\hline S08 & Ø20@150 mm & Ø16@150 mm & --- & 1.05 \\
\hline S09 & Ø22@150 mm & Ø16@150 mm & --- & 1.27 \\
\hline S10 & Ø25@150 mm & Ø16@150 mm & --- & 1.64 \\
\hline S11 & Ø16@150 mm & Ø16@150 mm & Ø12@100 mm & 0.67 \\
\hline S12 & Ø16@150 mm & Ø16@150 mm & Ø12@50 mm & 0.67 \\
\hline $\mathrm{S} 13$ & Ø16@150 mm & Ø16@150 mm & Ø10@50 mm & 0.67 \\
\hline
\end{tabular}

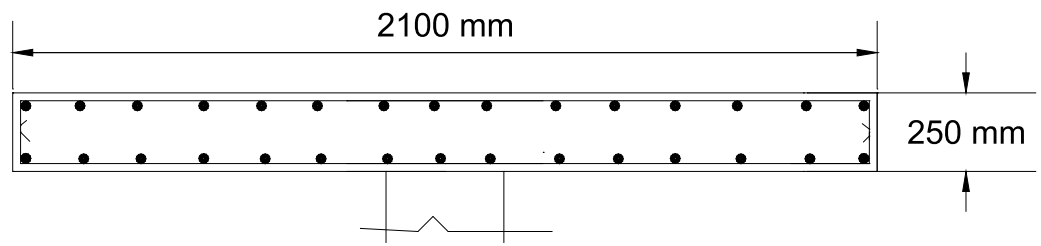

(a) Specimens $\mathrm{S} 01$ to $\mathrm{S} 10$

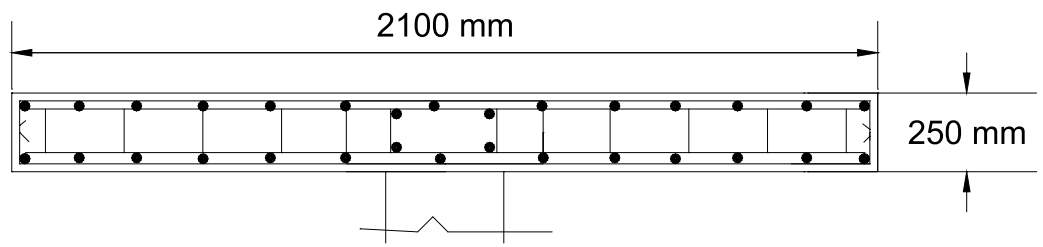

(b) Specimens S11 to S13

Fig. 9. Reinforcement details of the specimens.

\section{Results and discussion}

The specimens were divided into four groups A, B, C and D; each focusing on one parameter under study. This section discusses the results of the specimens computed using ANSYS 15 and in addition the results obtained were compared with the values calculated using E.C.P (203-2007) [5], ACI 318R-14 [6], and Eurocode2 [7]. Typical punching failure occurred in all the specimens as seen in Figure 10.

\subsection{Effect of horizontal flexural reinforcement}

Figures 11 and 12 show the load deflection relationships for groups (A) and (B). It can be seen from the figures that the horizontal flexural reinforcement ratio had a significant effect 
on the punching capacity. As the flexural reinforcement ratio was increased, the punching shear capacity increased which is in accordance with earlier experimental findings. Comparing specimens S01 and S05, the ultimate punching capacity increased by $18 \%$ when the reinforcement ratio was increased from $1 \%$ to $2.45 \%$. For group B, the punching capacity increased by $35 \%$ when the reinforcement ratio was increased from $0.67 \%$ to $1.64 \%$. In addition, the stress in the flexural reinforcement reached the first yield stress $\left(\mathrm{P}_{\mathrm{y}}\right)$ at larger load when the reinforcement ratio was increased. However, the value of the ultimate deflection decreased as the flexural reinforcement ratio increased indicating less ductility. Figure 13 shows the effect of flexure reinforcement ratio where the ultimate capacities of the ten slabs are plotted. It can be seen that the rate of increase in the punching capacity decreased as the reinforcement ratio increased. After reaching a certain reinforcement ratio, which in this case is $2 \%$, no significant increase in the ultimate punching capacity can be seen.

Table 3 shows the output results from the ANSYS as well as the comparison with the three design codes; E.C.P (203-2007) [5], ACI 318R-14 [6], and Eurocode2 [7]. The three design codes generally underestimated the punching capacity compared to that calculated using finite element analysis. The punching capacities estimated according to the E.C.P (203-2007) were the most conservative .The E.C.P (203-2007) [5] as well as the ACI 318R14 [6] do not take the effect of horizontal reinforcement into consideration which resulted in a fixed ultimate capacity value among the ten specimens despite the change in the reinforcement ratios. However, the output values using the Eurocode followed a similar pattern to the output obtained from ANSYS.

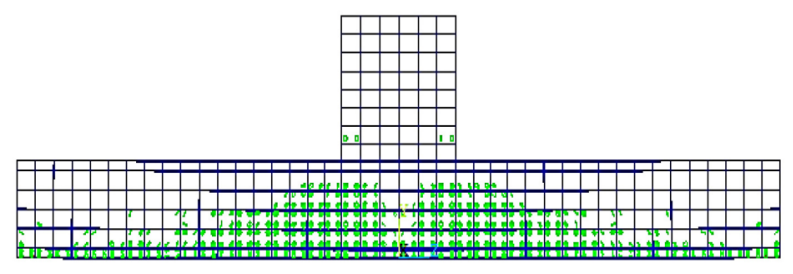

Fig. 10. Typical punching failure for specimen S06.
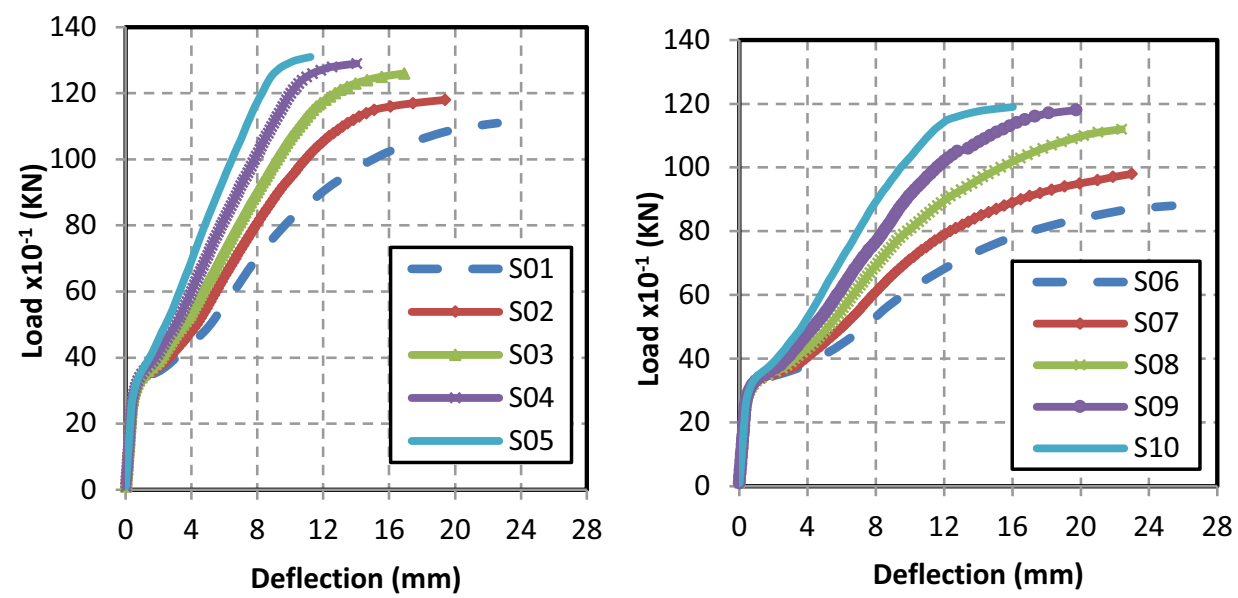

Fig. 11. Load - deflection curve for Group (A) Fig. 12. Load - deflection curve for Group (B) 


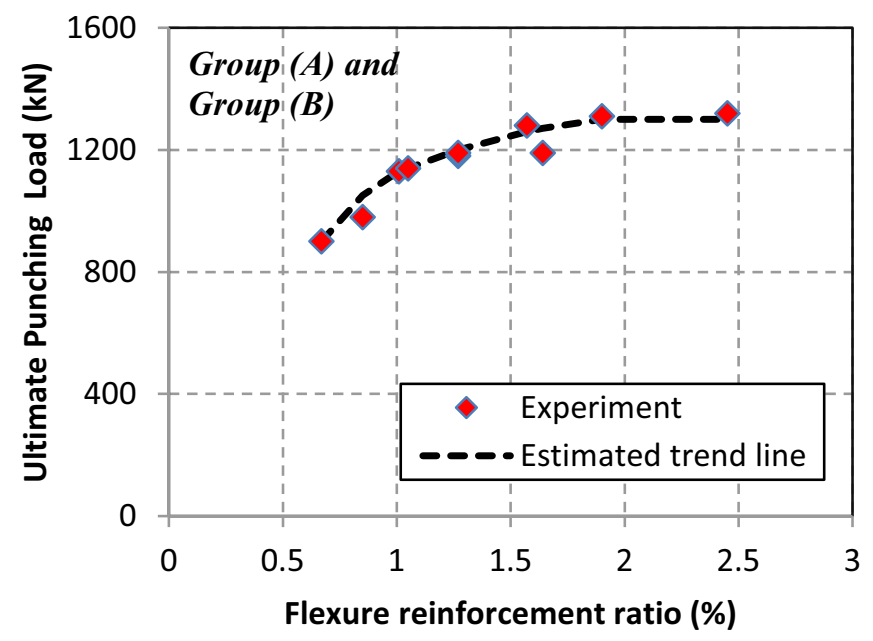

Fig. 13. Effect of horizontal reinforcement ratio on punching capacity.

Table 3. Analytical results - effect of horizontal reinforcement.

\begin{tabular}{|c|c|c|c|c|c|c|c|c|}
\hline \multirow{2}{*}{ 音 } & \multirow{2}{*}{ Specimen } & \multirow{2}{*}{ 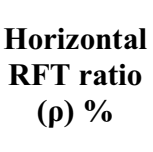 } & \multicolumn{3}{|c|}{ ANSYS } & \multirow{2}{*}{$\frac{\mathrm{ACI}}{\underset{(\mathrm{KN})}{\mathbf{P}_{\mathrm{u}}}}$} & \multirow{2}{*}{$\begin{array}{c}\text { Euro } \\
\begin{array}{c}P_{u} \\
(\mathrm{KN})\end{array}\end{array}$} & \multirow{2}{*}{$\begin{array}{c}\text { ECP } \\
\begin{array}{c}P_{\mathbf{u}} \\
(\mathrm{KN})\end{array}\end{array}$} \\
\hline & & & $\begin{array}{l}\mathbf{P}_{\mathbf{y}}{ }^{*} \\
(\mathbf{K N})\end{array}$ & $\begin{array}{l}\Delta_{\mathrm{u}}{ }^{* *} \\
(\mathbf{m m})\end{array}$ & $\underset{(\mathbf{K N})}{\mathbf{P u}_{\mathbf{u}}}$ & & & \\
\hline \multirow{5}{*}{$\sqrt{5}$} & S01 & 1.01 & 690 & 23 & 1110 & 708.4 & 649.5 & 619.2 \\
\hline & S02 & 1.27 & 830 & 19 & 1180 & 708.4 & 701.1 & 619.2 \\
\hline & S03 & 1.57 & 980 & 17 & 1260 & 708.4 & 752.4 & 619.2 \\
\hline & S04 & 1.90 & 1180 & 14 & 1290 & 708.4 & 801.8 & 619.2 \\
\hline & S05 & 2.45 & no & 11 & 1310 & 708.4 & 872.7 & 619.2 \\
\hline \multirow{5}{*}{ થิ } & S06 & 0.67 & 480 & 25 & 880 & 708.4 & 566.5 & 619.2 \\
\hline & S07 & 0.85 & 590 & 23 & 980 & 708.4 & 613.2 & 619.2 \\
\hline & S08 & 1.05 & 700 & 22 & 1120 & 708.4 & 658.0 & 619.2 \\
\hline & S09 & 1.27 & 840 & 20 & 1180 & 708.4 & 701.1 & 619.2 \\
\hline & S10 & 1.64 & 1040 & 16 & 1190 & 708.4 & 763.4 & 619.2 \\
\hline
\end{tabular}

${ }^{*} \mathrm{P}_{\mathrm{y}}$ Load corresponding to first yield stress. ${ }^{* *} \boldsymbol{\Delta}_{\mathrm{u}}$ Deflection at ultimate load.

\subsection{Effect of vertical shear reinforcement (Stirrups)}

Using vertical shear reinforcement increased the punching capacity of the tested slabs. It should also be noted here that the ACI computation in case of using stirrups gave ultimate punching load values closest to that obtained from the ANSYS.

\subsubsection{Effect of stirrups spacing}

The results for group (C) can be seen in Table 4 and Figure 14. Adding stirrups with spacing $100 \mathrm{~mm}$ which corresponds to $0.5 \mathrm{~d}$ resulted in an increase in the punching shear capacity of $4.5 \%$ compared to specimens with no shear reinforcement. While in case of spacing $50 \mathrm{~mm}(0.25 \mathrm{~d})$ the increase was $10.2 \%$ compared to S06. This can be attributed to the fact that smaller stirrups spacing give a higher area of steel resisting the punching stresses at the critical section 
Table 4. Analytical results - effect of stirrups spacing

\begin{tabular}{|c|c|c|c|c|c|c|c|c|c|}
\hline \multirow{2}{*}{$\stackrel{\Xi}{\Xi}$} & \multirow[b]{2}{*}{ Specimen } & \multicolumn{2}{|c|}{ Stirrups } & \multicolumn{3}{|c|}{ ANSYS } & \multirow{2}{*}{$\begin{array}{c}\mathbf{A C I} \\
\begin{array}{c}\mathbf{P}_{\mathbf{u}} \\
(\mathbf{K N})\end{array}\end{array}$} & \multirow{2}{*}{$\begin{array}{c}\text { Euro } \\
\begin{array}{c}\mathbf{P}_{\mathbf{u}} \\
(\mathrm{KN})\end{array}\end{array}$} & \multirow{2}{*}{$\begin{array}{c}\text { ECP } \\
\begin{array}{c}\mathbf{P}_{\mathbf{u}} \\
(\mathrm{KN})\end{array}\end{array}$} \\
\hline & & $\underset{(\mathbf{m m})}{\mathbf{S}}$ & $\begin{array}{c}\varnothing \\
(\mathbf{m m})\end{array}$ & $\begin{array}{c}\mathbf{P}_{\mathbf{y}} \\
(\mathbf{K N})\end{array}$ & $\underset{(\mathrm{mm})}{\Delta_{\mathrm{u}}}$ & $\begin{array}{c}\mathbf{P}_{\mathbf{u}} \\
(\mathbf{K N})\end{array}$ & & & \\
\hline \multirow{3}{*}{ (2) } & S06 & -- & -- & 480 & 25 & 880 & 708.4 & 566.5 & 619.2 \\
\hline & S11 & 100 & 12 & 520 & 31 & 920 & 1015.8 & 1224.0 & $\mathrm{~N} / \mathrm{A}$ \\
\hline & S12 & 50 & 12 & 520 & 44 & 970 & 1073.3 & 1224.0 & N/A \\
\hline
\end{tabular}

\subsubsection{Effect of stirrups diameter}

Similarly, increasing the bar diameter of the stirrups led to an increase in the load capacity as can be seen in Table 5 and Figure 15. Using diameter of $10 \mathrm{~mm}$ and $12 \mathrm{~mm}$ led to an increase in the punching capacity of $3.4 \%$ and $10.2 \%$, respectively compared to S06.

Table 5. Analytical results - effect of stirrups diameter.

\begin{tabular}{|c|c|c|c|c|c|c|c|c|c|}
\hline \multirow{2}{*}{ 产 } & \multirow{2}{*}{ Specimen } & \multicolumn{2}{|c|}{ Stirrups } & \multicolumn{3}{|c|}{ ANSYS } & \multirow{2}{*}{$\begin{array}{c}\text { ACI } \\
\mathbf{P}_{\mathbf{u}} \\
(\mathbf{K N})\end{array}$} & \multirow{2}{*}{$\begin{array}{c}\text { Euro } \\
\begin{array}{c}\mathbf{P}_{\mathrm{u}} \\
(\mathrm{KN})\end{array}\end{array}$} & \multirow{2}{*}{$\begin{array}{c}\text { ECP } \\
\begin{array}{c}P_{u} \\
(K N)\end{array}\end{array}$} \\
\hline & & $\underset{(\mathbf{m m})}{S}$ & $\underset{(\mathbf{m m})}{\varnothing}$ & $\begin{array}{l}\mathbf{P}_{\mathbf{y}} \\
(\mathbf{K N})\end{array}$ & $\begin{array}{c}\Delta_{\mathrm{u}} \\
(\mathbf{m m})\end{array}$ & $\begin{array}{c}\mathbf{P u}_{\mathbf{u}} \\
(\mathbf{K N})\end{array}$ & & & \\
\hline \multirow{3}{*}{$\widehat{\Theta}$} & S06 & -- & -- & 480 & 25 & 880 & 708.4 & 566.5 & 619.2 \\
\hline & S13 & 50 & 10 & 520 & 37 & 910 & 1073.3 & 1224.0 & $\mathrm{~N} / \mathrm{A}$ \\
\hline & S12 & 50 & 12 & 520 & 44 & 970 & 1073.3 & 1224.0 & $\mathrm{~N} / \mathrm{A}$ \\
\hline
\end{tabular}

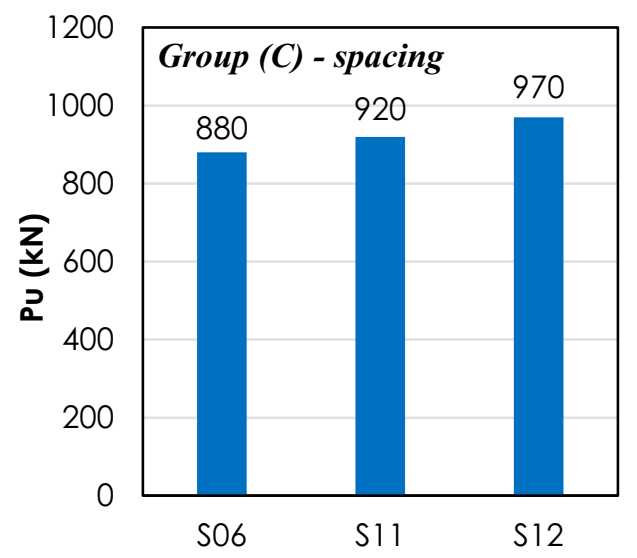

Fig. 14. Effect of stirrups spacing.

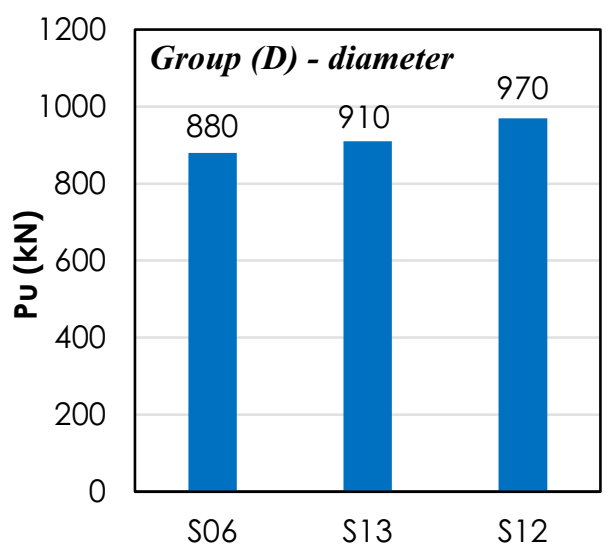

Fig. 15. Effect of stirrups diameter.

\section{Conclusions}

Based on the results of the study conducted on thirteen full scale flat slab specimens, the following conclusions can be drawn:

1. The ANSYS program is an effective tool that can be used to stimulate the punching behaviour of flat slabs. 
2. Studying full scale flat slab specimens with horizontal mesh spaced at $100 \mathrm{~mm}(0.5 \mathrm{~d})$, the ultimate punching capacity increased by $18 \%$ when the reinforcement ratio was increased from $1 \%$ to $2.45 \%$. While for the mesh spaced at $150 \mathrm{~mm}(0.7 \mathrm{~d})$, the ultimate punching capacity increased by $35.2 \%$ when the reinforcement ratio was increased from $0.67 \%$ to $1.64 \%$.

3. As the flexural reinforcement ratio increased, the value of the load at first yield increased but the ultimate deflection decreased.

4. The flexural reinforcement ratio has a significant effect on the ultimate punching capacity of flat slabs. However, the rate of increase in the punching capacity decreases as the reinforcement ratio increases.

5. For the vertical shear reinforcement, using bigger bar diameter and smaller spacing between stirrups increase the punching capacity. The increase in ultimate load capacity reached about $10 \%$ in the specimens studied.

6. When using vertical shear reinforcement, the spacing between stirrups is preferred to be limited to small values, $0.5 \mathrm{~d}$ or smaller, which is in accordance with the international design codes.

7. Results obtained using the E.C.P (203-2007), ACI318-14, and Eurocode2 differ according to the parameters considered in computation.

8. E.C.P (203-2007) has proven to be the most conservative among the three design codes while ACI318-14 gave reasonable results in case of using stirrups.

Deep gratitude and special thanks are given to Prof. Dr. Magdy E. Kassem for his continuous support and help throughout this research.

\section{References}

1. J. Moe, "Shearing Strength of Reinforced Concrete Slabs and Footings under Concentrated Loads," Development Department Bulletin D47, Portland cement Association, Skokie, Apr. (1961).

2. S. Kinnuen, H. Nylander, "Punching of Concrete Slabs without Shear Reinforcement," Transactions, No.158, Royal Institute of Technology, Stockholm, Sweden, (1960)

3. S. Kinnuen, "Punching of Concrete Slabs with Two-Way Reinforcement with Special Reference to Dowel Effect and Deviation of Reinforcement from Polar Symmetry", Transactions, No.198, Royal Institute of Technology, Stockholm, (1960).

4. J.L. Anderson, "Punching of concrete slabs with shear reinforcement", Transactions of the Royal institute of technology, No. 212, Stockholm, Sweden, (1963).

5. Egyptian Code for design and Construction of reinforced concrete structures, ECP 2032007 ed., Egypt, (2007)

6. ACI Committee 318, "Building Code Requirements for Structural Concrete (ACI 318-14) and Commentary (318R-14)," American Concrete Institute, Farmington Hills, MI, (2005).

7. Euro-Code 2, "Design of Concrete Structures, Part 1-1: General Rules and Rules for Buildings," CEN, EN 1992-1-1, Brussels, Belgium, (2004).

8. A. Hegab, R. Mabrouk, Ninth Alexandria International Conference on Structural and Geotechnical Engineering, AICSG9, RC-01, (2016).

9. A. Hegab, "Behavior of RC Flat Slabs with Horizontal and Vertical Shear Reinforcement in Punching". Master thesis, Structural Engineering Department, Faculty of Engineering, Cairo University, Egypt, (2016)

10. SAS IP, "ANSYS Theory Reference Release 5.6", ANSYS, Inc. Canonsburg, Pennsylvania, USA, (1999). 